\title{
3-Methyladenine suppresses cell migration and invasion of HT1080 fibrosarcoma cells through inhibiting phosphoinositide 3-kinases independently of autophagy inhibition
}

\author{
SHINGO ITO $^{1}$, NOBUKO KOSHIKAWA ${ }^{1}$, SHIGENOBU MOCHIZUKI ${ }^{2}$ and KEIZO TAKENAGA ${ }^{1}$ \\ Divisions of ${ }^{1}$ Chemotherapy and ${ }^{2}$ Biochemistry, Chiba Cancer Center Research Institute, \\ 666-2 Nitona, Chuoh-ku, Chiba 260-8717, Japan
}

Received March 12, 2007; Accepted April 26, 2007

\begin{abstract}
Methyladenine (3-MA) inhibits class III phosphoinositide 3-kinase (PI3K) and is widely used as an inhibitor of autophagy. 3-MA has also been shown to stimulate cell death of tumor cells under nutrient-starved conditions by inhibiting autophagy. To explore the possibility of this type of autophagy inhibitors as anticancer drugs, we examined the effects of 3-MA on the phenotypes of highly metastatic human fibrosarcoma HT1080 cells. We report here that although 3-MA did not markedly affect cell survival of the cells under either normal or amino acid-starved conditions, it strongly inhibited the invasiveness of the cells. 3-MA rapidly suppressed actin rich membrane ruffle and/or lamellipodia formation under normal conditions, leading to inhibition of cell migration and invasion of the cells without substantial inhibitions of small GTPase Rac activity and the production of matrix metalloproteinases MMP-2 and MMP-9. 3-MA abolished class I and class II PI3Ks in in vitro lipid kinase assays, and suppressed cell motility of the cells more strongly than the other PI3K inhibitors wortmannin and LY294002. Downregulation of Beclin 1, a protein required for autophagic body formation, by transfection of Beclin 1 siRNA did not inhibit membrane ruffle formation and cell migration. These results suggest that 3-MA suppresses the invasion of HT1080 cells, independently of autophagy inhibition, through inhibition of type I and II PI3Ks and possibly other molecules.
\end{abstract}

\section{Introduction}

Autophagy is a degradative mechanism mainly involved in the recycling and turnover of cytoplasmic constituents in

Correspondence to: Dr Keizo Takenaga, Division of Chemotherapy, Chiba Cancer Center Research Institute, 666-2 Nitona, Chuoh-ku, Chiba 260-8717, Japan

E-mail: keizo@chiba-cc.jp

Key words: 3-methyladenine, autophagy, PI3K, lamellipodia, migration, invasion eukaryotes, thus is essential for growth regulation and maintenance of homeostasis (1). Defective autophagy causes a number of pathological conditions including vacuolar myopathies, neurodegenerative diseases, liver disease, and some forms of cancer (2). The process is particularly induced when nutrients and/or growth factors are starved. During autophagy, damaged/obsolete cytoplasmic macromolecules and organelles are encapsulated by intracellular vesicles (autophagosomes), which subsequently fused with lysosomes, and are subjected to proteolysis (3). Many important molecules that regulate autophagy have been extensively studied in Saccharomyces cerevisiae, especially at genetic level (3), and related homologous proteins have been discovered in mammals including Beclin 1 (4). Beclin 1 forms a complex with class III phosphoinositide 3-kinase (PI3K) and functions at the trans-Golgi network (5). It is monoallelically deleted in human sporadic breast cancer, ovarian cancer, and prostate cancer (4). Moreover, Beclin $1^{+/}$mutant mice show a high incidence of spontaneous tumors and decreased autophagy (6).

There are several pharmacological inhibitors of autophagy. One of the most widely used inhibitor is 3-methyladenine (3-MA). It stops autophagy at the sequestration step in mammalian cells through inhibiting class III PI3K without markedly affecting protein synthesis or ATP levels (7-10). Recent studies have shown that 3-MA induces mucolipidoses type IV (11), inhibits formation of Francisella-containing vacuoles (12), blocks growth factor-withdrawal- and HIVenvelope glycoproteins-induced apoptotic process in $\mathrm{CD}^{+}$ $\mathrm{T}$ cells $(13,14)$, and suppresses amyloid $B$-protein in neuroblastoma cells exposed to hyperoxia (15). PI3K inhibitors such as wortmannin (WMN) and LY294002 have also been shown to inhibit autophagy (16).

Recent studies have shown the importance of autophagy in cancer $(17,18)$. When autophagy is inhibited using either chemical inhibitors including 3-MA or by RNA interference knockdown of autophagy molecules including Beclin 1 in tumor cells under nutrient-deprived conditions, the tumor cells undergo apoptosis (9), suggesting that autophagy may prevent the cells from cell death. In contrast, accumulation of autophagic vacuoles has been considered to be a marker of type II (autophagic) cell death as opposed to type I (apoptotic) cell death (18). Many anticancer agents such as etoposide, tamoxifen, rapamycin and ionizing radiation have 
been reported to induce autophagy, implying that autophagy may be a cause of cell death (19). Thus, the role of autophagy in cancer is complicated and is still a subject of debate.

In the present study, to explore the possibility of autophagy inhibitors as anticancer drugs, we treated highly metastatic human fibrosarcoma HT1080 cells under normal and nutrientstarved conditions with 3-MA. We found that although 3-MA only slightly enhances cell death of the cells under amino acid-starved conditions, it strongly suppresses their motility and invasion under normal culture conditions, thus implicating the application of this type of drugs to prevent invasion and metastasis.

\section{Materials and methods}

Cells and culture conditions. Human fibrosarcoma HT1080 cells were obtained from Health Science Research Resources Bank, Osaka. They were cultured in Dulbecco's modified Eagle's medium (DMEM) supplemented with $10 \%$ fetal bovine serum (FBS) or Hank's balanced salt solution (HBSS) supplemented with $10 \%$ dialyzed FBS (amino acid-starved medium).

Assay for apoptosis. Apoptosis was detected by Annexin V staining using Annexin V-EGFP Apoptosis Detection Kit (MBL, Nagoya) according to the manufacturer's instructions.

Visualization of autophagic vacuoles. Cells cultured in glassbottom culture dishes (MatTeck, Ashland, MA) were incubated with $50 \mu \mathrm{M}$ monodansylcadaverine (MDC) (Sigma-Aldrich, St. Louis, MO) in Dulbecco's PBS (DPBS) at $37^{\circ} \mathrm{C}$ for $10 \mathrm{~min}$ (20). After incubation, cells were washed three times with DPBS and immediately observed under an inverted fluorescence microscope (Olympus, Tokyo). Images were captured with a Cool SNAP charge-coupled device camera and processed using RS Image Express image processing software (Nippon Roper, Tokyo).

Immunofluorescent staining of F-actin. Cells on coverslips were fixed with $4 \%$ formaldehyde and $5 \%$ sucrose in DPBS for 30 min, permeabilized with $0.5 \%$ Triton X-100 in DPBS for $3 \mathrm{~min}$, and then incubated with $3 \%$ bovine serum albumin and $0.1 \%$ glycine in DPBS for $1 \mathrm{~h}$. For staining F-actin, the cells were incubated with Alexa Fluor ${ }^{\circledR} 568$ phalloidin (Molecular Probe, Eugene, OR) for $30 \mathrm{~min}$ at room temperature. For staining Beclin 1, the cells were incubated with polyclonal anti-Beclin 1 antibody (Santa Cruz Biotechnology, Inc., Santa Cruz, CA), washed with DPBS, and then incubated with FITC-labeled goat anti-rabbit IgG. After rinsing, the coverslips were mounted in $50 \%$ glycerol in DPBS containing $1 \mathrm{mg} / \mathrm{ml} p$-phenylenediamine to inhibit photobleaching.

Migration and invasion assays. Cell motility was measured by using $8-\mu \mathrm{m}$ pore size FluoroBlok transwell chambers (BD Sciences Labware, Franklin Lakes, NJ). Cells were collected by a brief treatment with trypsin/EDTA solution, washed once with serum-containing DMEM, centrifuged, resuspended in DMEM containing $0.1 \%$ bovine serum albumin, and then placed in the inserts at a concentration of $5 \times 10^{4}$ cells $/ 200 \mu 1$. In the lower compartment of the chamber, $750 \mu 1$ of DMEM containing $10 \%$ FBS was added as a chemoattractant. Invasion assay was carried out by the same procedure except that the filters of the transwell chambers were coated with $30 \mu \mathrm{g}$ Matrigel (Invitrogen Corp., Carlsbad, CA). After incubation at $37^{\circ} \mathrm{C}$ for $10 \mathrm{~h}$ (migration assay) or $24 \mathrm{~h}$ (invasion assay), HT1080 cells that migrated through the pores to the lower chamber were stained with $1 \mu \mathrm{M}$ Calcein AM (Molecular Probe) for $10 \mathrm{~min}$ and observed under a confocal laser microscope. In migration assays, the number of cells, which had migrated through the membranes, was counted on the pictures of at least three randomly selected fields. In invasion assays, all cells that had invaded through the Matrigel-coated membranes were counted.

Preparation of conditioned media and gelatin zymography. Cells $\left(3 \times 10^{5}\right.$ cells $/ \mathrm{ml}$ serum-free DMEM) were seeded onto 24-well tissue culture wells in the presence or absence of $10 \mathrm{mM}$ 3-MA. The conditioned medium was collected $24 \mathrm{~h}$ after seeding and analyzed for gelatin degrading activity by electrophoresis under non-reducing conditions on 9\% SDSpolyacrylamide gels containing $1 \mathrm{mg} / \mathrm{ml}$ gelatin. The volume of conditioned medium loaded per lane was standardized on the basis of cell number. After electrophoresis, the gels were washed twice with $200 \mathrm{ml}$ of $2.5 \%$ (v/v) Triton X-100 for $1 \mathrm{~h}$ at room temperature to remove SDS and then incubated at $37^{\circ} \mathrm{C}$ overnight in $50 \mathrm{mM}$ Tris- $\mathrm{HCl}, \mathrm{pH} 7.5,200 \mathrm{mM} \mathrm{NaCl}$, $5 \mathrm{mM} \mathrm{CaCl}_{2}$ and $0.02 \%(\mathrm{w} / \mathrm{v})$ Brij-35. The gels were stained with $0.5 \%(\mathrm{w} / \mathrm{v})$ Coomassie Brilliant Blue R-250 in 30\% (v/v) methanol, $10 \%(\mathrm{v} / \mathrm{v})$ acetic acid, and destained in the same solution without dye.

Transfection of Beclin 1 siRNA. siRNA mediated silencing of endogenous expression of Beclin 1 was performed using Beclin 1 siRNA (Santa Cruz Biotechnology). Beclin 1 siRNA was transfected with Lipofectamine 2000 according to the manufacturer's instructions (Invitrogen). Briefly, one day before transfection, cells were resuspended in 12-well plates in growth medium and then grown overnight. On the day of the experiment, siRNA-Lipofectamine 2000 complexes were prepared and transfection was performed according to the manufacturer's instructions. The cells were transfected with Beclin 1 siRNA for at least $5 \mathrm{~h}$ at $37^{\circ} \mathrm{C}$ before switching to fresh Opti-MEM containing 10\% FBS and incubated overnight. The medium was then changed to DMEM supplemented with $10 \%$ FBS. As a control for Beclin 1 siRNA, Silencer Negative Control \#1 siRNA (Ambion Inc., Austin, TX) was transfected.

Immunoblot analyses. Cells were lysed in 1\% Triton X-100, $1 \%$ sodium dodecylcholate, $0.1 \%$ SDS, $10 \mathrm{mM}$ Tris- $\mathrm{HCl}$, pH 7.4, $300 \mathrm{mM} \mathrm{NaCl}, 1 \mathrm{mM}$ EDTA and $1 \mathrm{mM}$ PMSF. After centrifugation at $10,000 \mathrm{~g}$ for $10 \mathrm{~min}$ at $4^{\circ} \mathrm{C}$, the supernatant was used for immunoblot analysis. Proteins were separated by SDS-PAGE under reducing conditions and transferred to a nitrocellulose membrane. After blocking with $5 \%$ dry milk in TBS-T $(150 \mathrm{mM} \mathrm{NaCl}, 50 \mathrm{mM}$ Tris- $\mathrm{HCl}, \mathrm{pH} 7.4$, and $0.05 \%$ Tween-20), the membrane was incubated with polyclonal anti-Beclin 1 antibody (Santa Cruz Biotechnology) or monoclonal anti-phospho-Akt (Ser473) antibody or anti-Akt antibody (Cell Signaling, Danvers, MA), washed extensively 
with TBS-T, and then incubated with horseradish peroxidase conjugated secondary antibodies. Immunodetection was carried out using the enhanced chemiluminescence system (ECL, Amersham Biosciences Corp., Buckinghamshire, UK). For a loading control, the membrane was stripped and reprobed with monoclonal anti- $\beta$-actin antibody (SigmaAldrich).

Rac activation assay. After 3-MA treatment, the cells were washed twice with DPBS and lysed in lysis buffer $(50 \mathrm{mM}$ Tris- $\mathrm{HCl}, \mathrm{pH} 7.5,10 \mathrm{mM} \mathrm{MgCl}_{2}, 0.5 \mathrm{M} \mathrm{NaCl}, 1 \%$ Triton $\mathrm{X}-100)$. The cell lysates were centrifuged at 10,000 $\mathrm{g}$ for $10 \mathrm{~min}$ at $4^{\circ} \mathrm{C}$, and the resultant supernatants $(500 \mu \mathrm{g}$ proteins $)$ were incubated with PAK-PBD-GST fusion protein beads (Cytoskeleton, Inc., Denver, $\mathrm{CO}$ ) at $4^{\circ} \mathrm{C}$ overnight. The beads were washed twice with the lysis buffer followed by two washings with wash buffer (25 mM Tris- $\mathrm{HCl}, \mathrm{pH} 7.5,30 \mathrm{mM}$ $\mathrm{MgCl}_{2}, 0.5 \mathrm{M} \mathrm{NaCl}$ ). The activated GTP-bound forms of Rac bound to beads and total Rac in cell lysates were detected by immunoblot using monoclonal anti-Rac1 antibody (BD Biosciences, San Jose, CA), as described above.

Analysis of PI3K activity. Class I, class II and class III PI3K activities were analyzed as described previously (21). Briefly, for analysis of class I PI3K activity, cells were washed with ice-cold buffer A (50 mM HEPES, pH 7.4, $150 \mathrm{mM} \mathrm{NaCl}$, $10 \mathrm{mM}$ EDTA, $10 \mathrm{mM} \mathrm{Na} \mathrm{P}_{2} \mathrm{O}_{7}, 100 \mathrm{mM} \mathrm{NaF}$ and $2 \mathrm{mM}$ $\mathrm{Na}_{3} \mathrm{VO}_{4}$ ), and extracted for $15 \mathrm{~min}$ at $4^{\circ} \mathrm{C}$ with buffer A supplemented with $0.5 \mathrm{mM}$ PMSF, $1 \%$ Nonidet P-40 (NP-40) and protease inhibitor cocktail (Roche Diagnostics, Mannheim). After centrifugation at $10,000 \mathrm{~g}$ for $10 \mathrm{~min}$ at $4^{\circ} \mathrm{C}$, the supernatants were immunoprecipitated with polyclonal anti-p85 class I PI3K (Santa Cruz Biotechnology) and Protein ASepharose beads for $2 \mathrm{~h}$ at $4^{\circ} \mathrm{C}$. The beads were washed twice with $1 \% \mathrm{NP}-40$ in DPBS, twice with $0.5 \mathrm{M} \mathrm{LiCl}$ in $100 \mathrm{mM}$ Tri-HCl (pH 7.4), and twice with $100 \mathrm{mM} \mathrm{NaCl}$ and $1 \mathrm{mM}$ EDTA in $10 \mathrm{mM}$ Tris- $\mathrm{HCl}(\mathrm{pH} \mathrm{7.4)}$. The beads were resuspended in $30 \mu 1$ buffer 1 (20 mM HEPES, pH 7.5, $0.4 \mathrm{mM}$ EGTA and $0.4 \mathrm{mM} \mathrm{Na}_{2} \mathrm{HPO}_{4}$ ), and supplemented with $10 \mu \mathrm{l}$ pre-sonicated phosphatidylinositol (PtdIns) $(1 \mu \mathrm{g} / \mu \mathrm{l})$ (Biomol, Plymouth Meeting, PA) in $5 \mathrm{mM}$ HEPES ( $\mathrm{pH}$ 7.5). The lipid kinase assay was started by adding $10 \mu 1$ of buffer 1 supplemented with $1 \mu \mathrm{Ci} / \mu 1\left[\gamma^{3}{ }^{32} \mathrm{P}\right] \mathrm{ATP}$ (GE Healthcare BioSciences Corp., Piscataway, NJ), $250 \mu \mathrm{M}$ ATP-Na ${ }_{2}$ and $50 \mathrm{mM}$ $\mathrm{MgCl}_{2}$. After 15 -min incubation at $37^{\circ} \mathrm{C}$, the reactions were stopped by adding $15 \mu \mathrm{l}$ of $4 \mathrm{M} \mathrm{HCl}$. Phospholipids were extracted with $130 \mu 1$ of chloroform/methanol $(1: 1, \mathrm{v} / \mathrm{v})$ and separated on Silica Gel 60A (Merck KGaA, Darmstadt) with chloroform/methanol/4.3 M ammonia (9:7:2, v/v/v). Phospholipids were identified by comparison with unlabeled phosphoinositide after exposure to iodine vapour. Radiolabeled PtdIns3P was detected by autoradiography. For analysis of class II PI3K, cells were disrupted by successive pumpings through a 26-gauge needle in $20 \mathrm{mM}$ Tris- $\mathrm{HCl}(\mathrm{pH} \mathrm{7.4)}$, $125 \mathrm{mM} \mathrm{NaCl}, 0.2 \mathrm{mM}$ EGTA, $0.2 \mathrm{mM}$ EDTA, $1 \mathrm{mM}$ $\mathrm{Na}_{3} \mathrm{VO}_{4}$ and protease inhibitor cocktail. After centrifugation of the cell lysates at $2,500 \mathrm{~g}$ for $10 \mathrm{~min}$ at $4^{\circ} \mathrm{C}$, the supernatant was further centrifuged at $100,000 \mathrm{~g}$ for $2 \mathrm{~h}$ at $4^{\circ} \mathrm{C}$. The resultant pellet was resuspended in buffer $2(20 \mathrm{mM}$ Tris- $\mathrm{HCl}$, pH 7.4, $125 \mathrm{mM} \mathrm{NaCl}, 0.2 \mathrm{mM}$ EGTA and 0.2 mM EDTA), and $30 \mu 1$ aliquots were supplemented with $10 \mu 1$ of sonicated PtdIns $(1 \mu \mathrm{g} / \mu \mathrm{l})$ and pre-incubated for $10 \mathrm{~min}$. The reaction was started by adding $10 \mu \mathrm{l}$ of $20 \mathrm{mM}$ Tris-HCl, pH 7.4, $125 \mathrm{mM}$ $\mathrm{NaCl}, 1 \mu \mathrm{Ci} / \mu 1\left[\gamma^{-32} \mathrm{P}\right] \mathrm{ATP}, 250 \mu \mathrm{M}$ ATP-Na 2 and $25 \mathrm{mM}$ $\mathrm{CaCl}_{2}$. After a 15 -min incubation at $37^{\circ} \mathrm{C}$, phospholipids were analysed as described above. For analysis of class III PI3K, cells were lysed in $20 \mathrm{mM}$ Tris- $\mathrm{HCl}, \mathrm{pH} 7.4,130 \mathrm{mM}$ $\mathrm{NaCl}, 1 \mathrm{mM}$ EDTA, $1 \mathrm{mM} \mathrm{Na} \mathrm{VO}_{4}, 1 \mathrm{mM}$ PMSF, $1 \%$ Triton $\mathrm{X}-100$ and protease inhibitor cocktail for $15 \mathrm{~min}$ at $4^{\circ} \mathrm{C}$. After centrifugation at $10,000 \mathrm{~g}$ for $10 \mathrm{~min}$ at $4^{\circ} \mathrm{C}$, the supernatants were immunoprecipitated with polyclonal anti-class III PI3K (Abcam, Cambridge) and protein A-Sepharose for $2 \mathrm{~h}$ at $4^{\circ} \mathrm{C}$. The beads were washed twice with the lysis buffer, and once with buffer $3(20 \mathrm{mM}$ Tris- $\mathrm{HCl}, \mathrm{pH} 7.4$, $130 \mathrm{mM} \mathrm{NaCl}$ and $0.2 \mathrm{mM}$ EDTA). The beads were resuspended in $30 \mu \mathrm{l}$ of buffer 3 supplemented with $10 \mu \mathrm{l}$ of sonicated PtdIns $(1 \mu \mathrm{g} / \mu \mathrm{l})$ and pre-incubated for $10 \mathrm{~min}$. The reactions were started by adding $10 \mu 1$ of buffer 3 supplemented with $1 \mu \mathrm{Ci} / \mu \mathrm{l}\left[\gamma^{-32} \mathrm{P}\right] \mathrm{ATP}, 250 \mu \mathrm{M}$ ATP-Na $\mathrm{Na}_{2}$ and $25 \mathrm{mM} \mathrm{MnCl}_{2}$. After a 15 -min incubation at $37^{\circ} \mathrm{C}$, phospholipids were analysed as described above.

\section{Results}

Effect of 3-MA on cell survival of HT1080 cells under normal and amino acid-starved conditions. First, we examined the status of autophagy in HT1080 cells under normal culture conditions. For this, the cells were incubated with the autofluorescent drug MDC, a specific autophagosome marker (20). We used HeLa cells as a reference because they are reported to be sensitive to and induced to die by 3-MA (10). The staining revealed that both cell types contained many MDC-labeled vacuoles in the cytoplasm (Fig. 1A). This result prompted us to test whether inhibition of autophagy affects cell survival of HT1080 cells under normal and amino acid-starved conditions. HT1080 cells were cultured in DMEM or HBSS (amino acid-starved) for $48 \mathrm{~h}$ in the presence or absence of $10 \mathrm{mM} 3-\mathrm{MA}$, at which concentration autophagy has been shown to be blocked (7-15). As shown in Fig. 1B, 3-MA only slightly enhanced cell death of HT1080 cells under normal conditions while it markedly stimulated that of HeLa cells (Fig. 1B). Supporting these results, apoptosis was not induced by 3-MA in HT1080 cells by $24 \mathrm{~h}$ after the treatment while it was markedly induced in HeLa cells (Fig. 1C). Under amino acid-starved conditions, both HT1080 and HeLa cells died to some extent within $48 \mathrm{~h}$. Again, 3-MA only slightly enhanced cell death of HT1080 cells (Fig. 1B). Thus, HT1080 cells were refractory to 3-MA compared to HeLa cells. We also examined the sensitivity of mammary carcinoma MDA-MB-231 and pancreatic carcinoma AsPC-1 cells to 3-MA and found that they were quite insensitive to 3-MA even under starved conditions (data not shown).

3-MA inhibits membrane ruffle formation in HT1080 cells under normal culture conditions. Although 3-MA did not significantly affect cell survival of HT1080 cells for at least $24 \mathrm{~h}$ under normal culture conditions, we noticed that it induced morphological changes accompanied by a significant reduction of membrane ruffle and/or lamellipodia formation 
A
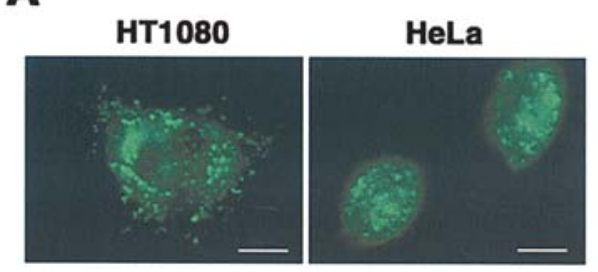

B

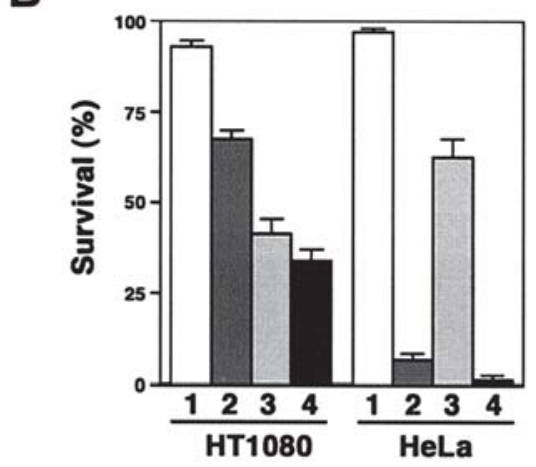

C

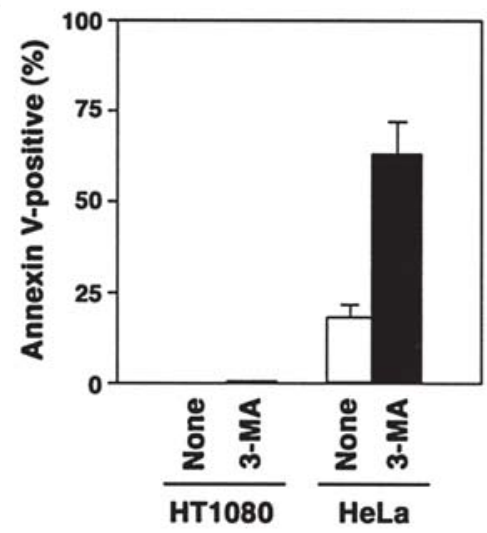

Figure 1. Effect of 3-MA on cell survival. (A) MDC-labeled autophagic vacuoles in HT1080 and HeLa cells under normal growth conditions. Pseudocolored. Scale bar, $20 \mu \mathrm{m}$. (B) Cell survival. HT1080 and HeLa cells were cultured in DMEM/10\% FBS (normal medium) (columns 1 and 2) or HBSS $/ 10 \%$ dialyzed FBS (amino acid-starved medium) (columns 3 and 4) in the absence (columns 1 and 3) or presence of $10 \mathrm{mM}$ 3-MA (columns 2 and 4 ) for $48 \mathrm{~h}$. Cell viability was determined by trypan-blue staining. Bars, SD. (C) Apoptosis. HT1080 and HeLa cells were cultured in normal medium with or without $10 \mathrm{mM}$ 3-MA for $24 \mathrm{~h}$. The number of annexin Vpositive cells was counted. Bars, SD.

(Fig. 2A and B). This was more clearly observed after staining F-actin with Alexa Fluor 568 phalloidine. The reduction in actin rich membrane ruffle formation was detected as early as $30 \mathrm{~min}$ after 3-MA treatment and further pronounced as the treatment time prolonged (Fig. 2C-F). HT1080 cells inherently have poorly organized actin stress fibers, and the actin stress fibers were further disorganized by 3-MA.

3-MA inhibits cell motility of HT1080 cells under normal culture conditions. Since membrane ruffle and/or lamellipodia formation is generally an indicator of cell migration, we examined the migratory ability of 3-MA-treated HT1080 cells. To this end, we employed Transwell migration assay in which FBS was used as a chemoattractant. Counting of the
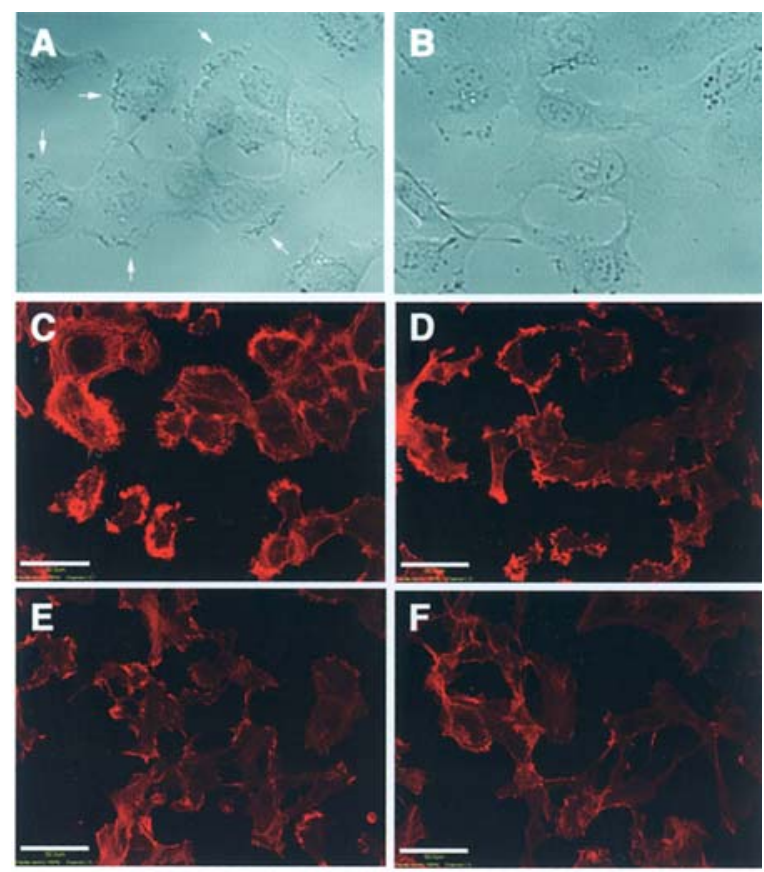

Figure 2. Effect of 3-MA on membrane ruffle formation. (A and B) Phase contrast images of HT1080 cells. The cells were cultured in the absence (A) or presence (B) of $10 \mathrm{mM} 3-\mathrm{MA}$ for $8 \mathrm{~h}$. Arrows indicate membrane ruffles and/or lamellipodia. (C-F) HT1080 cells were cultured in the absence (C) or presence of $10 \mathrm{mM} 3-\mathrm{MA}$ for $0.5 \mathrm{~h}(\mathrm{D}), 1 \mathrm{~h}(\mathrm{E})$ or $2 \mathrm{~h}(\mathrm{~F})$. The cells were stained with Alexa Fluor 568 phalloidin, and then observed under a confocal laser microscope. Scale bar, $50 \mu \mathrm{m}$.

cells that migrated through the pores to the lower surface of the filters during a 10-h incubation period revealed that 3-MA (5-10 mM) strongly inhibited cell migration (Fig. 3A). 3-MA also inhibited cell migration of human lung adenocarcinoma A549 and MDA-MB-231 cells (data not shown), suggesting that 3-MA inhibits the migration of a variety of cell lines.

Small GTPase Rac is an important effector of PI3K and has been found to regulate membrane ruffle and/or lamellipodia formation and cell motility (22). To examine whether 3-MA treatment could reduce Rac activity, we treated HT1080 cells with $10 \mathrm{mM} \mathrm{3-MA}$ for up to $2 \mathrm{~h}$, and the intracellular concentration of the active GTP-bound form of Rac was measured. The data showed that 3-MA did not change the amount of GTP-Rac (Fig. 3B).

We next compared the effect of 3-MA on cell migration with those of WMN and LY294002. As show in Fig. 3C, both $100 \mathrm{nM}$ WMN and $25 \mu \mathrm{M}$ LY294002 suppressed cell migration of HT1080 cells, in agreement with the previous report (23). However, their effect was weaker than that of 10 mM 3-MA.

3-MA inhibits the invasion of HT1080 cells. The above results suggested that 3-MA could inhibit the invasion of HT1080 cells. Then we performed Matrigel invasion assays, and found that it significantly inhibited the invasive ability of the cells (Fig. 4A).

To test whether 3-MA affects the secretion of MMPs, which are essential for tumor cells to invade, we carried out gelatin zymography. Results showed that HT1080 cells secreted three major MMP activities (assigned as proMMP-9, 
A

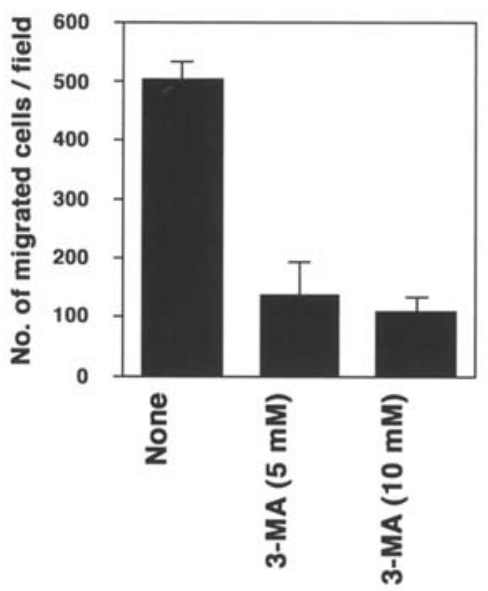

B

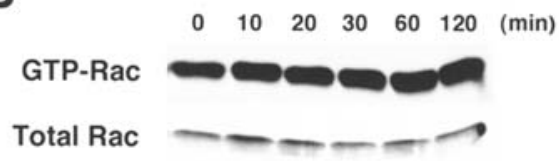

C

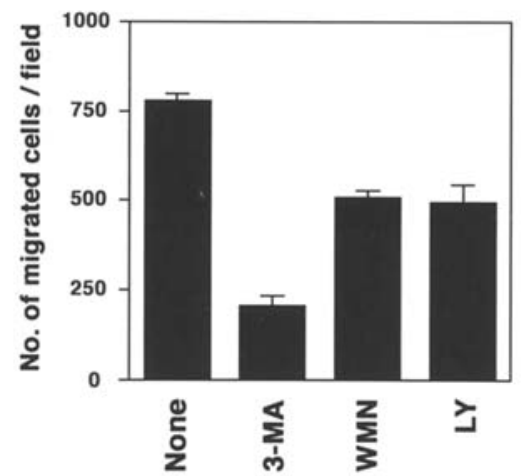

Figure 3. Effects of 3-MA on cell migration. (A) Migration assay. HT1080 cells were subjected to transwell migration assays in the absence or presence of $5 \mathrm{mM}$ or $10 \mathrm{mM} 3-\mathrm{MA}$ for $10 \mathrm{~h}$. The number of migrated cells was counted on the pictures of at least three randomly selected fields. Bars, SD. (B) Pulldown assay of activated Rac. The GTP-bound form of Rac was pulled down with GST fusion proteins, corresponding to the p21-binding domain (PBD) of human PAK-1, conjugated to agarose beads. The GTP-Rac proteins bound to the beads were identified using anti-Rac antibody by Western blotting. Cell lysates were also subjected to immunoblot analysis to detect Rac. (C) Comparison of the inhibitory effect of 3-MA, WMN and LY294002 on cell migration. HT1080 cells were subjected to transwell migration assays in the absence or presence of $10 \mathrm{mM} 3-\mathrm{MA}, 100 \mathrm{nM} \mathrm{WMN}$ or $25 \mu \mathrm{M}$ LY294002 (LY). Bars, SD.

proMMP-2 and activated MMP-2, based on size) into the culture medium, which are completely abolished in the presence of the MMP inhibitor 1, 10-phenanthroline (Fig. 4B). 3-MA slightly suppressed the secretion of proMMP-9, but showed virtually no effect on the secretion of proMMP-2 and activated MMP-2. Thus, the inhibition of invasion by 3-MA is likely to be due to the suppression of cell motility.

Downregulation of Beclin 1 does not suppress cell migration of HT1080 cells. To examine whether autophagy inhibition itself is associated with the suppression of membrane ruffling and cell motility, we transfected Beclin 1 siRNA into HT1080
A
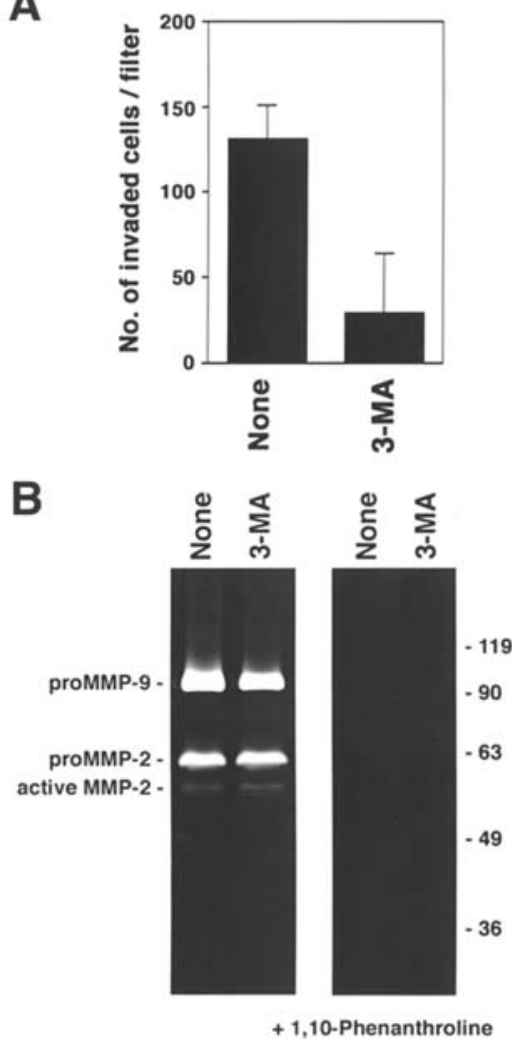

Figure 4. Effects of 3-MA on invasion and MMP secretion. (A) Invasive ability. HT1080 cells were subjected to Matrigel invasion assays in the absence or presence of $10 \mathrm{mM} \mathrm{3-MA}$ for $24 \mathrm{~h}$. All the cells that had invaded through the Matrigel-coated membranes were counted. Bars, SD. (B) MMP secretion. HT1080 cells were cultured for $24 \mathrm{~h}$ in the absence or presence of $10 \mathrm{mM}$ 3-MA. MMPs secreted into the conditioned medium were analyzed by gelatin zymography. 1, 10-Phenanthroline was used as an MMP inhibitor.

cells. Immunoblot analysis demonstrated that the expression of Beclin 1 was suppressed by the siRNA (Fig. 5A). As expected, the number of cells with MDC-labeled vacuoles was decreased in the siRNA-transfected cells (Fig. 5B). Immunofluorecent staining showed that Beclin 1 was concentrated at the perinuclear region (Fig. 6), consistent with the previous report (5). Transfection of Beclin 1 siRNA resulted in the disappearance of perinuclear staining. However, membrane ruffle formation was still observed in the Beclin 1 knockdown cells (Fig. 6). Furthermore, the migratory ability of the cells was completely refractory to the siRNA treatment (Fig. 5C).

3-MA inhibits class II PI3K as well as class I and III PI3Ks. 3 -MA is known to directly inhibit class III PI3K $(8,16)$. It was also demonstrated to inhibit phosphorylation of ribosomal S6 protein, suggesting the inhibition of class I PI3K (16). To obtain information about the mechanism underlying the inhibition of cell motility by 3-MA, we carried out in vitro PI3K activity assays, according to the previous protocol (21), especially focusing on the effect on class II PI3K activity. Results showed that $10 \mathrm{mM}$ 3-MA inhibited class III PI3K as potent as $100 \mathrm{nM}$ WMN (Fig. 7A). 3-MA also inhibited class I PI3K as effective as $100 \mathrm{nM}$ WMN. This was further corroborated by the inhibition of phosphorylation of Akt, a downstream target of class I PI3K. 3-MA inhibited Akt 
A

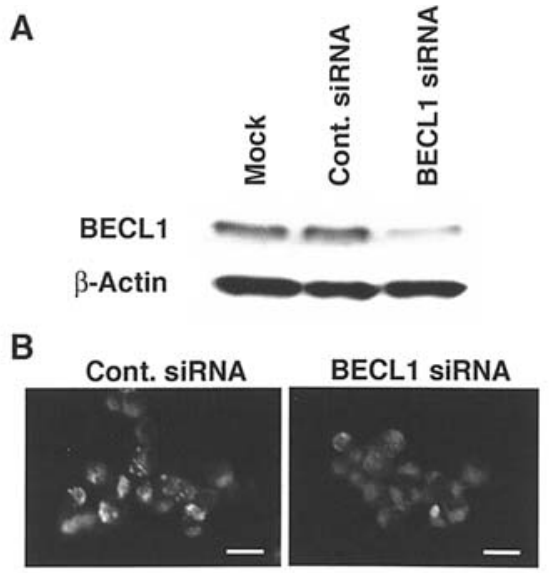

C

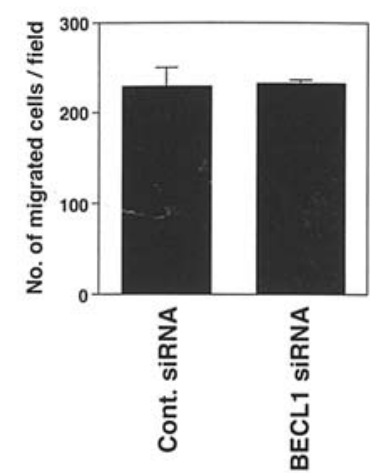

Figure 5. Effects of siRNA-mediated knockdown of Beclin 1 on autophagy and cell motility. (A) Immunoblot analysis of Beclin 1 expression. HT1080 cells were mock-transfected or transfected with $50 \mathrm{nM}$ control (Cont.) siRNA or $50 \mathrm{nM}$ Beclin 1 (BECL1) siRNA. Cell lysates were prepared $48 \mathrm{~h}$ after the transfection, and subjected to immunoblot analysis using anti-Beclin 1 antibody. (B) MDC labeling of autophagosomes. Cont. siRNA or BECL1 siRNA-transfected HT1080 cells were stained with MDC and visualized under a fluorescence microscope. Scale bar, $100 \mu \mathrm{m}$. (C) Migration assay. Cont. siRNA or BECL1 siRNA-transfected HT1080 cells were subjected to transwell migration assays. Bars, SD.
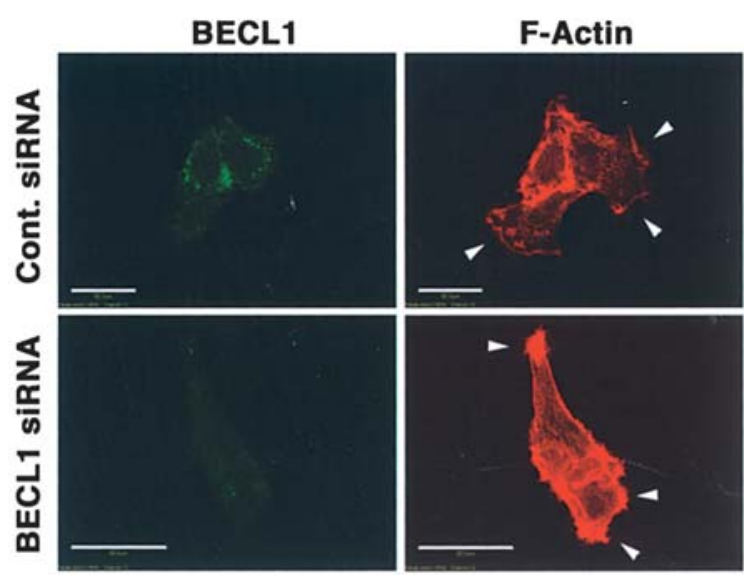

Figure 6. Effect of 3-MA on membrane ruffle formation. HT1080 cells were transfected with $50 \mathrm{nM}$ control (Cont.) siRNA or $50 \mathrm{nM}$ Beclin 1 (BECL1) siRNA. Forty-eight hours later, the cells were double stained for Beclin 1 and F-actin. Arrowheads indicate membrane ruffles and/or lamellipodia. Scale bar, $50 \mu \mathrm{m}$.

phosphorylation within 10 min after the treatment (Fig. 7B). 3-MA (10 mM), WMN (100 nM) and LY294002 $(25 \mu \mathrm{M})$ were equally effective in inhibiting the phosphorylation of
A

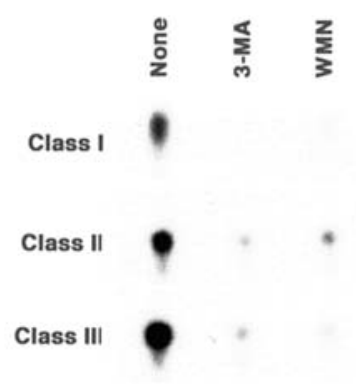

B
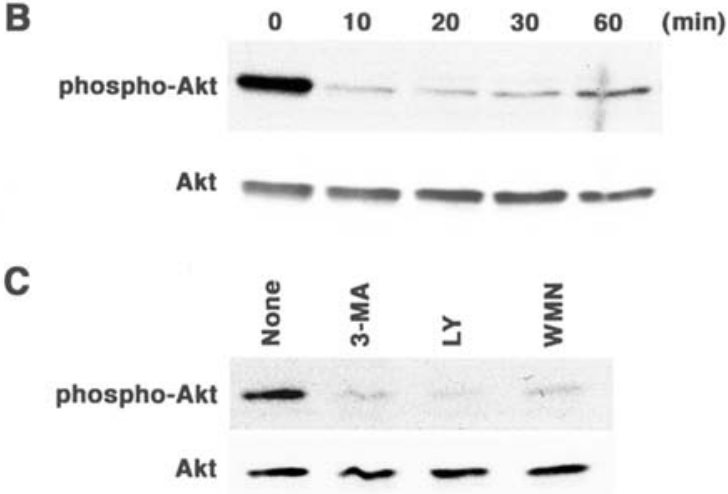

Figure 7. Effects of 3-MA on PI3K activities and Akt phosphorylation. (A) PI3K assays. Class I, class II and class III PI3K activities were assayed using cell lysates of HT1080 cells as described in Materials and methods. Ten mM 3-MA or $100 \mathrm{nM}$ WMN was included in the lipid kinase assays. The data are the representative of two independent experiments in which similar results were obtained. (B) Time-course of the effect of 3-MA on Akt phosphorylation. HT1080 cells were treated with $10 \mathrm{mM} \mathrm{3-MA}$ for the indicated times. Cell lysates were prepared and subjected to immunoblot analysis using monoclonal anti-Akt or anti-phospho-Akt antibody. (C) Effects of 3-MA, WMN and LY294002 on Akt phosphorylation. HT1080 cells were treated with $10 \mathrm{mM} 3-\mathrm{MA}, 25 \mu \mathrm{M}$ LY294002 (LY) or $100 \mathrm{nM}$ WMN for $4 \mathrm{~h}$. Cell lysates were prepared and subjected to immunoblot analysis using monoclonal anti-Akt or anti-phospho-Akt antibody.

Akt in the cells (Fig. 7C). Intriguingly, 3-MA was found to inhibit class II PI3K (Fig. 7A). Thus, 3-MA was found to be able to inhibit all classes of PI3Ks.

\section{Discussion}

The present results showed that both HT1080 and HeLa cells contained a large number of autophagic vacuoles under normal culture conditions, indicating the occurrence of active recycling and turnover of cytoplasmic constituents. Supporting the previous report, 3-MA massively induced cell death in HeLa cells especially under starved conditions (18). These results suggest that autophagy prevents the cells from cell death. Unlike HeLa cells, 3-MA only slightly enhanced cell death of HT1080 cells during a 48-h-incubation period under normal culture conditions and starved conditions as well. In addition, MDA-MB-231 and AsPC-1 cells were quite refractory to 3-MA even under starved conditions for at least $48 \mathrm{~h}$. Thus, autophagy inhibitors might be useful for killing tumor cells, yet depending on the cell types and circumstances.

The present study also demonstrated that 3-MA directly inhibits class I PI3K activity in vitro. In accordance with this, 3-MA inhibited Akt phosphorylation in vivo. We also demonstrated for the first time that 3-MA inhibits class II 
PI3K. Therefore, 3-MA is found to be able to inhibit all classes of PI3Ks. Thus far, three mammalian class II PI3K isoforms, PI3K-C2 $\alpha$, PI3K-C2 $\beta$ and PI3K-C $2 \gamma$, have been characterized (24). Both PI3K-C2 $\alpha$ and $\mathrm{PI} 3 \mathrm{~K}-\mathrm{C} 2 \beta$ are ubiquitously expressed, whereas PI3K-C $2 \gamma$ is predominantly expressed in the liver (24). Little is known about how these enzymes are activated, but PI3K-C $2 \alpha$ lies downstream of the monocyte chemotactic peptide 1 chemokine receptor (25), the insulin receptor (26), and the epidermal growth factor (EGF) receptor (24). PI3K-C2B is activated following stimulation of the EGF receptor or platelet-derived growth factor (PDGF) receptor with EGF or PDGF, respectively (24). Of all of these class II PI3Ks, PI3K-C $2 \alpha$ is most refractory to WMN. Because more than $90 \%$ of class II PI3K activity in HT1080 cells was abolished by $100 \mathrm{nM}$ WMN, PI3K-C2B may be the dominant isoform expressed in the cells. Our data showed that $10 \mathrm{mM}$ 3-MA inhibited class II $\mathrm{PI} 3 \mathrm{~K}$ activities as potent as $100 \mathrm{nM}$ WMN. Therefore, it is plausible that 3-MA can inhibit at least PI3K-C2ß activity. Whether 3-MA is able to inhibit PI3K-C2 $\alpha$ and PI3K-C2 $\gamma$ remains to be examined.

Interestingly, we found that 3-MA suppressed membrane ruffle formation in HT1080 cells as early as 30 min after the treatment under normal culture conditions. Moreover, it inhibited cell migration and invasion of HT1080 cells. It is not yet precisely known how 3-MA suppresses membrane ruffle formation and cell migration of HT1080 cells. Autophagy inhibition itself may not be involved in the mechanism because siRNA-mediated suppression of the expression of Beclin 1 did not inhibit membrane ruffle formation and cell migration. As evidenced by Akt phosphorylation, class I PI3K is constitutively activated in HT1080 cells. Endogenous Akt is localized at the leading edge of migrating HT1080 cells and controls cell migration in a PI3K-dependent manner (23). Moreover, PI3K-C2ß has recently been shown to regulate cytoskeletal organization and cell migration $(27,28)$. Therefore, together with the fact that WMN and LY294002 suppressed cell migration of HT1080 cells, it is plausible that 3-MA suppresses the migration through inhibiting, at least in part, class I PI3K and PI3K-C2ß.

PI3K signaling pathway contributes to the activation of Rho family small GTPases RhoA, Rac1 and Cdc42 that are known to modulate distinct cytoskeletal rearrangements necessary for cell motility (22). The formation of lamellipodia, filopodia, and stress fibers is often associated with cell migration. HT1080 cells have been shown to exhibit both mesenchymal and amoeboid types of cell migration that are dependent on Rac and Rho signaling, respectively (22). PI3K-C2ß is probably stimulated in HT1080 cells because the cells constitutively express PDGF and PDGF receptors (29). These facts together with the present observations suggested that 3-MA might inhibit the activation of Rac in HT1080 cells. However, we could not detect any change in the activation state of Rac in 3-MA-treated cells, indicating that the level of Rac constitutive activity is PI3K-independent. Presumably, the level is mediated by the mutant N-Ras protein expressed in the cells, as suggested previously (29).

Our results suggest that irrespective of nearly equal potency of $10 \mathrm{mM} 3-\mathrm{MA}$ and $100 \mathrm{nM}$ WMN with regard to the inhibition of PI3Ks, 3-MA was more effective in inhibiting cell migration. This suggests that, in addition to PI3Ks, 3-MA may inhibit other signaling molecule(s) responsible for regulating cell motility. Identification of such molecules might lead to finding novel targets for efficient inhibition of tumor invasion and metastasis.

\section{Acknowledgements}

This work was supported in part by Grant-in-Aid from the Ministry of Health, Labour, and Welfare for Third Term Comprehensive Control Research for Cancer and from the Ministry of Education, Culture, Sports, Science and Technology, Japan.

\section{References}

1. Kilionsky DJ and Emr SD: Autophagy as a regulated pathway of cellular degradation. Science 290: 1717-1721, 2000.

2. Kelekar A: Autophagy. Ann NY Acad Sci 1066: 259-271, 2005.

3. Mizushima N, Ohsumi Y and Yoshimori T: Autophagosome formation in mammalian cells. Cell Struct Funct 27: 421-429, 2002.

4. Liang XH, Jackson S, Seaman M, et al: Induction of autophagy and inhibition of tumorigenesis by beclin 1 . Nature 402: 672-676, 1999.

5. Kihara A, Kabeya Y, Ohsumi Y and Yoshimori T: Beclinphosphatidylinositol 3-kinase complex functions at the transGolgi network. EMBO Rep 2: 330-335, 2001.

6. Qu X, Yu J, Bhagat G, et al: Promotion of tumorigenesis by heterozygous disruption of the beclin 1 autophagy gene. J Clin Invest 112: 1809-1820, 2003

7. Petiot A, Ogier-Denis E, Blommaart EF, Meijer AJ and Codogno P: Distinct classes of phosphatidylinositol 3'-kinases are involved in signaling pathways that control macroautophagy in HT-29 cells. J Biol Chem 275: 992-998, 2000.

8. Seglen PO and Gordon PB: 3-Methyladenine: specific inhibitor of autophagic/lysosomal protein degradation in isolated rat hepatocytes. Proc Natl Acad Sci USA 79: 1889-1892, 1982.

9. Lum JJ, Bauer DE, Kong M, et al: Growth factor regulation of autophagy and cell survival in the absence of apoptosis. Cell 120: 237-248, 2005.

10. Boya P, Gonzalez-Polo RA, Casares N, et al: Inhibition of macroautophagy triggers apoptosis. Mol Cell Biol 25: 1025-1040, 2005.

11. Jennings JJ Jr, Zhu JH, Rbaibi Y, Luo X, Chu CT and Kyselyov K: Mitochondrial aberrations in mucolipidosis type IV. J Biol Chem 281: 39041-39050, 2006.

12. Checroun C, Wehrly TD, Fisher ER, Hayes SF and Celli J: Autophagy-mediated reentry of Francisella tularensis into the endocytic compartment after cytoplasmic replication. Proc Natl Acad Sci USA 103: 14578-14583, 2006.

13. Li C, Capan E, Zhao Y, et al: Autophagy is induced in $\mathrm{CD} 4^{+} \mathrm{T}$ cells and important for the growth factor-withdrawal cell death. J Immunol 177: 5163-5168, 2006.

14. Espert L, Denizot M, Grimaldi M, et al: Autophagy is involved in $\mathrm{T}$ cell death after binding of HIV-1 envelope proteins to CXCR4. J Clin Invest 116: 2161-2172, 2006.

15. Zheng L, Roberq K, Jerhammar F, Marcusson J and Terman A: Oxidative stress induces intralysosomal accumulation of Alzheimer amyloid B-protein in cultured neuroblastoma cells. Ann NY Acad Sci 1067: 248-251, 2006.

16. Blommaart EF, Krause U, Schellens JP, Vreeling-Sindelarova $\mathrm{H}$ and Meijer A: The phosphatidylinositol 3-kinase inhibitors wortmannin and LY294002 inhibit autophagy in isolated rat hepatocytes. Eur J Biochem 243: 240-246, 1997.

17. Hippert MM, O'Toole PS and Thorburn A: Autophagy in cancer: good, bad, or both? Cancer Res 66: 9349-9351, 2006.

18. Kondo $\mathrm{Y}$ and Kondo S: Autophagy and cancer therapy. Autophagy 2: 85-90, 2006.

19. Kondo Y, Kanzawa T, Sawaya R and Kondo S: The role of autophagy in cancer development and response to therapy. Nat Rev Cancer 5: 726-734, 2005.

20. Munafo DB and Colombo MI: A novel assay to study autophagy: regulation of vacuole size by amino acid deprivation. J Cell Sci 114: 3619-3629, 2001. 
21. Tassa A, Roux MP, Attaix D and Bechet DM: Class III phosphoinositide 3-kinase-Beclin 1 complex mediates the amino acid-dependent regulation of autophagy in $\mathrm{C} 2 \mathrm{C} 12$ myotubes. Biochem J 376: 577-586, 2003.

22. Yamazaki D, Kurisu S and Takenawa T: Regulation of cancer cell motility through actin reorganization. Cancer Sci 96: 379-386, 2005.

23. Kim D, Kim S, Koh H, et al: Akt/PKB promotes cancer cell invasion via increased motility and metalloproteinase production. FASEB J 15: 1953-1962, 2001.

24. Arcaro A, Zvelebil MJ, Wallasch C, Ullrich A, Waterfield MD and Domin J: Class II phosphoinositide 3-kinases are downstream targets of activated polypeptide growth factor receptors. Mol Cell Biol 20: 3817-3830, 2000

25. Turner SJ, Domin J, Waterfield MD, Ward SG and Westwick J: The CC chemokine monocyte chemotactic peptide- 1 activates both the class I p85/p110 phosphatidylinositol 3-kinase and the class II PI3K-C2 $\alpha$. J Biol Chem 273: 25987-25995, 1998.
26. Brown RA, Domin J, Arcaro A, Waterfield MD and Schepherd PR: Insulin activates the $\alpha$ isoform of class II phosphoinositide 3 kinase. J Biol Chem 274: 14529-14532, 1999.

27. Maffucci T, Cooke FT, Foster FM, et al: Class II phosphoinositide 3-kinase defines a novel signaling pathway in cell migration. J Cell Biol 169: 789-799, 2005.

28. Katso RM, Pardo OE, Palamidessi A, et al: Phosphoinositide 3-kinase $C 2 \beta$ regulates cytoskeletal organization and cell migration via Rac-dependent mechanisms. Mol Biol Cell 17: 3729-3744, 2006.

29. Gupta S, Stuffrein S, Plattner R, et al: Role of phosphoinositide 3-kinase in the aggressive tumor growth of HT1080 human fibrosarcoma cells. Mol Cell Biol 21: 5846-5856, 2001. 